\title{
On the Practical Impossibility of Being Both Well-Informed and Impartial
}

\author{
SVEINUNG S. SIVERTSEN \\ University of Bergen
}

\begin{abstract}
Adam Smith argued that the ideal moral judge is both wellinformed and impartial. As non-ideal moral agents, we tend only to be truly well-informed about those with whom we frequently interact. These are also those with whom we tend to have the closest affective bonds. Hence, those who are well-informed, like our friends, tend to make for partial judges, while those who are impartial, like strangers, tend to make for ill-informed ones. Combining these two traits in one person seems far from straightforward. Still, if becoming well-informed is, as Smith also claims, a matter of imaginative perspective-taking with the "person principally concerned" (TMS, I.i.1.4, 13), it might be possible to become well-informed without the emotional entanglement that comes from any actual proximity to those we judge. Against this intuition, I use Construal Level Theory to show that the tension between being well-informed and impartial is likely to persist even if we take any actual proximity out of the equation. I end by discussing some implications of this, and suggest that we should consider revising the ideal to accommodate them.
\end{abstract}

Keywords: Adam Smith, impartial, well-informed, conventionalism, Construal Level Theory, proximity, bias, perspective-taking

JEL Classification: A110, B120, B310, B400

\section{INTRODUCTION}

In The Theory of Moral Sentiments, Adam Smith argues that an ideal moral judge must be both impartial and well-informed (TMS, III.2.32, 150-151). ${ }^{1}$ This sounds intuitively right, and much of the secondary

\footnotetext{
${ }^{1}$ This and all subsequent references to The Theory of Moral Sentiments, abbreviated as 'TMS', will be to the Cambridge edition (Smith 2002). References include, in this order, part, section (if applicable, in lower case roman numerals), chapter, and paragraph (both in Arabic numerals).
}

AUTHOR's Note: Thanks to Preben Sørheim and the other people at the Department of philosophy at the University of Bergen who have commented on earlier drafts of this article. Thanks also to the two anonymous reviewers for their extremely helpful and constructive criticism, and to the editors at EJPE for their support. 
literature on TMS assumes that moral agents can in fact live up to this ideal and be both impartial and well-informed. As an example, take the debate about conventionalism: this debate is concerned with whether an individual can transcend the conventional standard of propriety into which she or he has been socialised, by means of reflecting on what an impartial and well-informed spectator would approve of. ${ }^{2}$ As such, the debate rests on the assumption that persons can, in fact, adopt the perspective of such a spectator.

Fonna Forman (2010) has challenged this assumption by pointing out a tension between the two traits of this spectator. According to Smith, being impartial requires a certain affective distance, while being well-informed typically presupposes a degree of physical proximity. However, physical proximity tends to breed affective proximity, thus precluding impartiality. Hence, friends may be the best-informed spectators, but they also tend to be the most partial. Conversely, strangers may be the most impartial spectators, but they also tend to be the least-informed. Smith's ideal, Forman complains, is "essentially Janus-faced", requiring us to be close and distant at the same time (Forman-Barzilai 2010, 159).

Still, Forman has left the door ajar for those who might want to salvage the impartial spectator-and the reason to want to do so extends beyond the debate about conventionalism. The impartial spectator also represents a non-ideal alternative to later Ideal Observer Theories. To its adherents, the fact that the impartial spectator is a realistic ideal, something we can in fact adopt and inhabit, is also what makes it a usable ideal for everyday moral deliberation. If the impartial spectator turns out not to be realistic in this sense, then it also ceases to be an attractive alternative.

Forman, I hinted, has left the door ajar. In her telling of the tension between understanding and impartiality, the tension is primarily mediated by proximity in physical space. However, according to Smith, the main tool of the moral judge is her imagination, and our imagination can "bring home" (TMS, I.i.4.6, 26) to us the cases of people we have never met. With physical space thus taken out of the equation, might not the tension also be eased or eliminated? Unfortunately, no-or so I will argue. The reason is that the proximity bias in our moral judgements also extends to perceived or psychological proximity.

\footnotetext{
${ }^{2}$ To take but three examples, see Samuel Fleischacker (2011), Carola Freiin von Villiez (2011), and Christel Fricke (2011).
} 
Psychological proximity, moreover, is the inevitable result of the imaginative process involved in becoming well-informed-of "bringing the case home" (TMS, I.i.1.4, 13).

Hence, the tension between understanding and impartiality runs deeper than previously recognised. This presents a serious problem both for those who argue for the convention-transcending potential of the impartial spectator, and for those who see Smith's ideal as a realistic alternative to Ideal Observer Theories for everyday moral deliberation. I end by briefly considering how we might respond to this problem.

\section{Proximity Bias}

That spatial relations shape our moral judgements has been a topic in ethics at least since the ancient Stoics. The Stoics noted how we tend to sympathise more readily with those who are close to us, so that the strength of our moral concern declines progressively as we move outward in what may be visualised as concentric circles representing, simultaneously, physical and affective proximity. First, there is the inner circle of close family and friends, then, moving outwards, acquaintances, neighbours, compatriots, and, outermost, humanity as a whole. These are the "circles of sympathy" (Forman-Barzilai 2010, 8-9). Smith adopts the Stoic image, and the connection between physical proximity and moral concern crops up in Smith's choice of the "spectator" as the model moral judge (TMS, I.i.1.4, 13). For, in Smith's standard case of moral judgement, the spectator is physically close enough to see with her own eyes what the "person principally concerned" is going through (TMS, I.i.1.4, 13; Forman-Barzilai 2010, 142).

Yet, for all the importance of the faculty of vision to Smith's model (Griswold 2010, 68), it is, Smith argues, only with the help of our imagination that what we see can be transformed into an understanding of what someone else is going through-namely through imagining what we ourselves would feel if we were them:

Though our brother is upon the rack, as long as we ourselves are at our ease, our senses will never inform us of what he suffers. They never did, and never can, carry us beyond our own person, and it is by the imagination only that we can form any conception of what are his sensations. Neither can that faculty help us to this any other way, than by representing to us what would be our own, if we were in his case. By the imagination we place ourselves in his situation, we conceive ourselves enduring all the same torments, we enter as it 
were into his body, and become in some measure the same person with him, and thence form some idea of his sensations, and even feel something which, though weaker in degree, is not altogether unlike them. His agonies, when they are thus brought home to ourselves, when we have thus adopted and made them our own, begin at last to affect us, and we then tremble and shudder at the thought of what he feels. (TMS, I.i.1.2, 11-12; my emphases)

Our senses prompt our imagination, which in turn carries us 'beyond our own person', 'bringing home' and bringing alive to us the agony of 'our brother'. Physical proximity, that is, helps determine both how likely we are to try to imagine ourselves in someone else's shoes, and how likely we are to succeed in so doing. The former because our senses continually prompt our sympathetic imagination, and so what is close enough to be sensed will also tend to lay claim to most of our sympathetic bandwidth. The latter because direct sensory perception also affords us with the "minutest incidents" Smith thought vital to wellinformed moral judgement (TMS, I.i.4.6, 26; Forman-Barzilai 2010, 143, 159) - the kind of evocative detail we seldom imagine spontaneously by ourselves, but which appears to play an important role in determining whether we are able to feel, as opposed to merely think, what it must be like to be in someone else's shoes (Gilbert and Wilson 2007, 1345; see also Levine, Lench, and Safer 2009, 1060).

Therefore, even though physical proximity is neither necessary nor sufficient for sympathy (Forman-Barzilai 2010, 144-145), we will, typically, be both more ready and more able to sympathise with those who are physically close enough to be seen or sensed. As Forman puts it, "the dominant strain in Smith's thought regarding physical space is that physical proximity makes contact likelier and sympathy therefore more precise" (Forman-Barzilai 2010, 145-146). Repeated interactions tend to reinforce this pattern, forging friends from acquaintances (Forman-Barzilai 2010, 153; Nahemow and Lawton 1975; Newcomb 1956). And from friends, the best-informed spectators (TMS, I.i.4.9, 28; Forman-Barzilai 2010, 159; see also Stinson and Ickes 1992).

However, it is not from our friends that we can expect to learn the real truth of how an impartial spectator would see us. Friends are too interested in our well-being to judge us with the degree of "indifference" that is required for impartially (TMS, II.i.2.2, 81; III.2.32, n22, 152); they care too much about us as individuals to see us as "but one in the multitude in no respect better than any other in it" (TMS, II.ii.1.1, 97; 
III.3.4, 158). Consequently, they tend to be too indulgent with our foibles and transgressions (Forman-Barzilai 2010, 159). For truly impartial judgements, we therefore have to turn to strangers, who have no special interests in us (TMS, I.i.4.9, 28; III.3.38, 178; Forman-Barzilai 2010, 159). The trouble is that what the stranger gains in terms of impartiality by her affective distance, she also loses in terms of understanding by the physical remoteness that grants her this indifference (Forman-Barzilai 2010, 159).

Friends, then, tend to be well-informed but partial, while strangers tend to be impartial but ill-informed. It is far from clear how any single person could combine the two into one and be both impartial and wellinformed at the same time (Forman-Barzilai 2010, 160).

Far from clear-but perhaps not impossible. For, if it is true that the tension between understanding and impartiality is primarily mediated by physical proximity, what happens if we bypass physical space entirely? Could the tension then also be eliminated? If the impartial spectator familiarises herself with the case of a distant stranger, not by coming into close physical contact with him, but through learning about his situation and vividly imagining it from a distance-would her wellinformed judgements of him necessarily end up being partial as well? This seems much less certain. It is one thing to say that close friends typically both understand and are too understanding of each other, quite another to say that knowledge and affection are entangled in such a way as to make the trade-off between understanding and impartiality inevitable.

It may seem less certain, but, as we shall see, it is likely true. The reason lies hidden within the metaphor of bringing the case home. Let us therefore begin by examining that metaphor more closely.

\section{BRINGING THE CASE HOME}

Throughout TMS, Smith employs the metaphor of bringing the case home as a shorthand for the imaginative work involved in becoming well-informed. In Part I, where he establishes the basics of his moral psychology, the metaphor is embedded in a description that makes clear just how demanding this work can be:

He must adopt the whole case of his companion with all its minutest incidents; and strive to render as perfect as possible, that imaginary 
change of situation upon which his sympathy is founded. (TMS, I.i. $4.6,26)^{3}$

To understand this quote, we need some background on Smith's moral psychology. Smith begins TMS by noting that people are not wholly selfish-we do in fact care about each other (I.i.1.1, 11). The psychological principle that underlies this other-care is, according to Smith, our capacity for "sympathy", which he defines as "fellow-feeling with any passion whatever" (I.i.1.5, 13), or what we today would ordinarily call empathy: by imaginatively taking your perspective, I get some sense of what you must be going through. ${ }^{4}$

However, our capacity for sympathy is not simply a capacity to share other people's feelings. Rather, it is a capacity that allows us to evaluate those feelings by comparing them to how we ourselves feel when we imagine being in their place:

The man who resents the injuries that have been done to me, and observes that I resent them precisely as he does, necessarily approves of my resentment. The man whose sympathy keeps time to my grief, cannot but admit the reasonableness of my sorrow [...] [h]e who laughs at the same joke, and laughs along with me, cannot well deny the propriety of my laughter. (TMS, I.I.3.1, 20)

More generally, if you observe me reacting to something, you are first disposed to look for that something to explain my behaviour (I.i.1.9, 14-15). When casting about for a candidate cause, you may find one that you can imagine reacting to similarly if you were me. If this also appears to be the actual cause of my reaction, you will find that you share my appraisal of the situation, and hence that you sympathise with my sentiments. If you were me, you would have reacted (more or less) as I have in fact done, and hence you also approve of my sentiments as "suitable to their objects", as appropriate (I.i.3.1, 20). ${ }^{5}$ If, on the contrary, you are unable to sympathise with my sentiments, finding them

\footnotetext{
${ }^{3}$ See also TMS, I.i.1.2, 12; I.i.1.4, 13; I.i.1.7, 14; I.i.2.6, 20; I.i.3.1, 20; I.i.3.9, 23; I.i.5.2, 29; II.i.2.5, 83; II.i.3.3, 85; II.i.5.3, 88; II.i.5.3a11, 91; II.i.5.6, 89; II.1.2, 128; V.2.5, 237; VI.ii.3.1, 276; VII.iii.1.4, 374.

4 'Ordinarily' because the precise meaning of that term is contested in ways which need not concern us here (see for example Coplan 2011; Jahoda 2005).

${ }^{5}$ A spectator may of course also, upon recognising that she sympathises with the agent, be appalled at her own reaction, worrying, say, that she harbours the same racist attitudes as expressed by the agent (Broadie 2006, 172). In so doing, however, she is taking the perspective of a spectator on her own reaction, repeating the process of sympathetic spectatorship.
} 
"unsuitable to the causes which excite them" (I.i.3.1, 20), you disapprove of my sentiments as inappropriate to the degree that you find you would have reacted differently:

If my animosity goes beyond what the indignation of my friend can correspond to; if my grief exceeds what his most tender compassion can go along with; [...] if I laugh loud and heartily when he only smiles, or, on the contrary, only smile when he laughs loud and heartily; in all these cases, as soon as he comes from considering the object, to observe how I am affected by it, according as there is more or less disproportion between his sentiments and mine, I must incur a greater or lesser degree of his disapprobation: and upon all occasions his own sentiments are the standards and measures by which he judges of mine. (TMS, I.i.3.1, 20-21)

Hence, all our judgements about what is appropriate-that is, moral-behaviour are ultimately predicated on the presence or absence of sympathy. If I sympathise with you, I approve, and I judge your actions appropriate. If I do not sympathise with you, I disapprove, and I judge your actions inappropriate.

If Smith is right about this relationship between sympathy and judgements of propriety, then it follows that we must do some serious imaginative footwork to qualify as moral judges. ${ }^{6}$ We must, that is, always be ready to bring home to ourselves the case of the other, be ready to imagine their situation 'with all its minutest incidents' to feel how we would react if we were them. If we do not, we are not in a position to say whether our sympathy or lack thereof really corresponds to the propriety or impropriety of the action in question; our judgement might be wrong because we are ill-informed. As we shall see, it is this bringing home that creates the deepest tension between understanding and impartiality.

\section{Construal LeVel Theory}

The perspective-taking component of what Smith called sympathy, and we today call empathy, is often construed as a kind of going visiting, in the sense that we imaginatively transpose ourselves into the situation of the person whose perspective we take. We talk of "walking" or being in another's "shoes" (Darwall 1999, 143), seeing with another's "eyes"

\footnotetext{
${ }^{6}$ There is some empirical evidence to support Smith's account of the operation of sympathy; see Hepach and Westermann (2013).
} 
(TMS, I.i.4.8, 28), and of taking an "allocentric" perspective (Wong and Wyer 2016, 17). In this light, the metaphor of bringing the case home seems a curious companion, since it picks out a movement in the opposite direction. Research on the interrelations between the level of detail in which we consider something and the perceived closeness of that thing sheds some light on why the two apparently opposed movements involved in sympathising-going visiting and bringing home-nonetheless hang together. It all comes down to movements along what Yaacov Trope and Nira Liberman call "dimensions" of "psychological distance" (2010, 440).

The idea of psychological distance originates in a simple observation: we only directly experience the here and now, and yet things that are not here and now-for example, memories of the past and plans for the future-occupy a large part of our thinking (Trope and Liberman 2010, 440). Our capacity for such "mental time travel" has been extensively studied (see for example Suddendorf and Corballis $2007,299)$, but we also spend a considerable amount of time thinking about things that are spatially removed from us, about other people, and about things that could have happened or are more or less likely to happen. Trope and Liberman therefore suggest conceptualising psychological distances as extending outward from our selves in the present, in four interrelated dimensions: temporal, spatial, social, and hypothetical (Trope and Liberman 2010, 442-443). In a manner of speaking, then, our minds are multidimensional psychological spaces.

This psychological space is populated by what we think about-or, in the parlance of social psychology, by mental construals (Trope and Liberman 2010, 440). To take a non-moral example: I can think about the holiday to Italy that my girlfriend and I have planned for next year, and my trip to Germany coming up in a few days' time. Thinking about each of them brings them both into my psychological space, but, crucially, I perceive the trip to Italy as temporally more distant than the one to Germany.

A central claim of Construal Level Theory (CLT) is that this difference in perceived temporal distance relates to the way I think about each trip, to the way I construe it. When I think about the future trip to Italy, I will tend mostly to focus on general features such as enjoying the sun, exploring, and so on. My mental construal of the temporally distant trip will tend to be abstract and involve "high level" features of what I imagine (Trope and Liberman 2010, 441). In contrast, 
thinking of my trip to Germany two days from now, I will tend to focus on details like what to pack, and at what time I have to leave from home to reach the airport in time. My mental construal of the temporally closer trip will tend to be concrete and involve "low level" features of what I imagine (Trope and Liberman 2010, 441). ${ }^{7}$

However, if I put aside the details of my trip to Germany for the moment and think instead of the purpose or goal of the trip-typical high-level construals-the trip may appear temporally more distant, like there is still plenty of time to prepare everything (an effect known as the 'planning fallacy'-see Kruger and Evans 2004; see also Nussbaum, Liberman, and Trope 2006, 159). Conversely, if I get my act together and actually sit down to book tickets to Italy, the shift in focus from highlevel pleasantness to the low-level details of our itinerary may make next summer seem a little less distant. In other words, the link between construal level and psychological distance is bidirectional (Liberman et al. 2007). Therefore, our perceived or psychological distance to something is the result of a dynamic interaction between factors outside our control, like actual temporal distance, and something over which we have some control, namely, the way we construe the thing we are thinking about.

Thus, going visiting and bringing home both point to a reduction in psychological distance, a traversing of the psychological space between the spectator and the person principally concerned. ${ }^{8}$ If we translate Smith's injunction to "adopt the whole case of [our] companion with all its minutest incidents" (TMS, I.i.4.6, 26) into CLT-ese, it reads as an instruction to traverse the psychological distance between ourselves and our companion by forming a detailed, low-level construal of her situation. However, doing so is not without consequence for our ability to judge her impartially.

\section{Construal LeVEl TheORY AND MORAL JudgeMENT}

Research has revealed that construal level affects moral judgements (for a recent, if incomplete review, see Mårtensson 2017). The first study to

\footnotetext{
${ }^{7}$ There may be cultural differences here. See Messervey (2008), but compare Wong and Wyer $(2016,30)$.

${ }^{8}$ There may be some relevant differences between the two; see the related discussion of the difference between "imagine-self" and "imagine-other" (Batson et al. 2003, 1192), and the two kinds of self-other overlap discussed by Galinsky, Ku, and Wang (2005); though I agree with Heidi L. Maibom that any strict separation between these two modes of sympathetic/empathetic imagination is somewhat artificial (Maibom 2017, 6).
} 
examine this connection, by Eyal, Liberman, and Trope (2008), found that people would judge moral transgressions more severely if the transgressions were construed as taking place in the more distant future (see their Study 2). ${ }^{9}$ This may surprise you: should we not react more strongly towards something that is closer at hand-perhaps because it is more threatening or more vivid? The proposed explanation is based on the fact that moral norms are themselves high-level constructs. Because of this, a high-level construal of a given situation can more easily be brought under the category of a moral norm, compared to the concrete, low-level construals we make of events that are psychologically closer (Eyal and Liberman 2012, 188-189; Eyal, Liberman, and Trope 2008, 1208, and their Study 1). ${ }^{10}$

Take lying as an example. The concept of a lie can be seen as having a prototypical structure. This means that we have some idea of a prototypical instance of a lie, and that we extend this idea in various directions to incorporate other, less central cases (Johnson 2014, 91-98). If, then, we are confronted with something that might be a lie, and we construe the case in abstract, high-level terms, then aspects of the case that may align it with the prototypical lie-what we take to be the speaker's intention, for example-will feature prominently in our thinking about it. At the same time, the details of the case will not be considered, details that might have distinguished this case from the prototype and pointed towards other, less morally problematic highlevel descriptions, like a white lie or an ironic comment. Thus, high-level construals may make us trigger-happy in our moral judgements.

\footnotetext{
${ }^{9}$ Specifically, participants read vignettes adapted from Haidt (2001) and Haidt, Koller, and Dias (1993) on such things as eating the family dog, consensual sexual intercourse between siblings, and cleaning a house with the national flag, as well as on a married woman having an affair, and a student cheating on an exam (Studies 1-3). Similar vignettes describing morally virtuous actions were also used (Study 4). Each vignette described what the authors say is a moral violation/morally virtuous action (high-level information) as well as contextual details that moderated the offensiveness/virtuousness of that violation (low-level information). Psychological distance was manipulated either by instructing participants to imagine the events taking place tomorrow/in a year (temporal distance), or from their own perspective/that of a third person (social distance). The effect of stronger moral judgements (negative and positive) with increased psychological distance was consistent across experiments. From the point of view of a moral philosopher, the use of vignettes describing purported 'moral violations' that are not necessarily immoral, such as cleaning one's house with the national flag, is problematic. Fortunately, other studies have replicated the effect using less controversially moral/immoral examples, such as giving to charity/stealing (Agerström and Björklund 2013a, 2013b).

${ }^{10}$ A related explanation is that increased psychological distance leads to increased 'dispositionalism'; that is, the tendency to ascribe people's behaviours to traits rather than circumstance, see Agerström and Björklund (2009, Experiment 3).
} 
In general, the greater the psychological distance, the more abstract the construal. The more abstract the construal, the fewer the details that can distinguish the present case from the prototypical moral transgression. The fewer the details that can distinguish it from a prototypical moral transgression, the easier it is to categorise it as a moral transgression. The easier it is to categorise it as a moral transgression, the easier it is to condemn it-possibly in error. Conversely, the smaller the psychological distance, the more the contextual details of the situation occupy our thinking about it, the less likely we are simply to categorise it as an instance of a prototypical moral transgression, and the less likely we are to condemn it, whether rightly or in error. Thus, if these findings hold, it would be an empirical demonstration of the old saying, tout comprendre rend tres indulgent. ${ }^{11}$

These effects have been replicated (Mårtensson 2017 counts 12 congruent findings), but the opposite has also been found (Gong and Medin 2012), complicating the picture. Specifically, Gong and Medin manipulated construal level by asking subjects to consider the "why" (high-level) versus the "how" (low-level) of a moral transgression (2012, 629 ), and found that moral judgements were stronger for low-level construals (replicated in Žeželj and Jokić 2014). Responding to these findings, Eyal, Liberman, and Trope (2014) tested and found that the why-manipulation induces participants to search for explanations for why someone committed a moral transgression, which they argue serve as mitigating circumstances.

Therefore, the direction of the effect-weakening or strengthening moral judgement-may depend on whether psychological proximity and/or low-level construals lead to emphasis on mitigating or exacerbating circumstances. In Eyal, Liberman, and Trope (2008) the contextual details were designed to be mitigating, but the opposite could of course also be true. Indeed, Williams, Stein, and Galguera (2014) found that greater psychological proximity was correlated with a stronger affective response to the situation. If that response is negative, as it is apt to be in cases of serious moral transgressions, psychological proximity could lead to harsher judgements in spite of the reduced salience of a general moral norm covering the act in question. Hence, even though it may often be true that tout comprendre rends tres

${ }^{11}$ The expression is usually given as tout comprendre c'est tout pardonner, but the version from Germaine de Staël's Corinne ou l'Italie (1807, quoted in Thorstensen 2011) fits the context better. 
indulgent, "understanding"-as P. F. Strawson remembers J. L. Austin remarking-"might just add contempt to hatred" (Strawson 1985, 39 n5).

The point, however, remains: construal level and psychological distance affect our moral judgements. We judge the same case differently depending on whether we construe it in low-level detail or high-level abstraction, as psychologically proximate or psychologically distant. ${ }^{12}$ In other words, the problematic entanglement of affective and physical space extends into psychological space. In a weak sense, the tension between impartiality and understanding is also reproduced. As soon as we bring home to us the case of some particular person, we treat her differently to all those whose cases we have not thus brought home to ourselves; we no longer treat her as "but one in the multitude" (TMS, II.ii.2.1, 97).

There is also a stronger sense in which the tension picked out by Forman is perpetuated in psychological space: four of the studies reviewed by Mårtensson (2017) investigated the effect of social distance on moral judgement. All these, including the only high-power replication study in the field (Žeželj and Jokić 2014), found that social proximity leads to weaker moral judgement. A fifth study not mentioned by Mårtensson may serve as an illustration of the effect. In a series of experiments, Gino and Galinsky (2012) found that inducing perceived social proximity between participants and the people they judged would lead participants both to make more lenient judgements of immoral acts, and be more disposed to acting in an immoral manner themselves. For example, simply getting participants to perspective-take with someone who had acted selfishly (by keeping to themselves a reward that could be split) would lead participants to judge the selfish action less harshly, in turn increasing participants' own intention to act selfishly (Experiment 1). ${ }^{13}$ This is the same kind of indulgence Forman picked out as the threat to impartiality that arises from close physical contact. In other words, the very act of bringing the case home, of imagining ourselves in the place of another, will tend to make us more indulgent towards those we judge. ${ }^{14}$

${ }^{12}$ We may also judge groups of people differently, see Luguri, Napier, and Dovido (2012).

${ }^{13}$ Interestingly, the effect was less pronounced for generous actions (Experiment 4).

${ }^{14}$ Including, it would seem, when we judge ourselves; see Conway and Peetz (2012) for a link between construal level, moral licensing, and moral reinforcement. 
There is, possibly, a further, still stronger sense in which psychological proximity perpetuates proximity bias in our moral judgements. For, if becoming well-informed really requires us to bring home to us the case of another in all its minutest incidents, then the brute fact of cognitive limitations-specifically, limitations on the number of "chunks" of information that we can hold in our working memory at any given time (Cowan 2001, 88; Mesoudi, Whiten, and Dunbar 2006; Meyer, Taylor, and Lieberman 2015; Stiller and Dunbar 2007) - seems to entail that we will only be able to imagine, in requisite detail, the situation of a single person at any given time..$^{15}$ In a conflict involving two or more people, therefore, it seems we would judge the relative merit of each of their claims differently depending on whose case we last brought home to ourselves. ${ }^{16}$ Hence, even if we understand impartiality narrowly as equal consideration of the interests of those directly involved in a case, our ability to judge impartially may be threatened by bias arising from a purely psychological proximity.

This, admittedly, is the most speculative of my proposals, and my overall argument does not depend on it being sound. Neither does my overall argument ride on CLT offering the best description of the effect of psychological proximity on moral judgement. Williams and Bargh (2008), for example, argue that the effect can be explained by how metaphors based on physical space shape our thinking (but see Pashler, Coburn, and Harris 2012 for a replication failure). Yet, the overall effect they aim to explain remains the same: psychological distance and/or construal level affect judgements, including moral judgements. Whether the effect is primarily cognitive or affective, mediated by changes in construal level (low-level, 'minutest incidents') or psychological distance (near-social, bring the case home), and one of stronger or weakerharsher or more lenient-moral judgement, the overall effect appears to be robust. The implication is also the same: taking physical (or any kind

\footnotetext{
${ }^{15}$ Stiller and Dunbar found that people could keep track of five orders of intentionality (including their own) at the same time, which, interestingly, correlates with the typical number of close friends (5). However, the task involved very simple chunks of information. Thus, for the fifth level of intentionality, the sequence to remember ran as follows: "Jenny thought that Emma hoped that the boss would believe that the chemist wanted Emma to work for him" (Stiller and Dunbar 2007, 102). Impressive as this may be, it does not include the kind of 'minutest incidents' that Smith wants us to heed in the exercise of our sympathetic imagination.

${ }^{16}$ Indeed, this effect is tacitly recognised in the rule, observed in some legal traditions, of letting the defendant have the last word in court (for a paradoxical consequence of this, further underlining the complexity of moral and legal judgements, see Englich, Mussweiler, and Strack 2005).
} 
of actual) distance out of the equation does not eliminate the tension between understanding and impartiality.

\section{IMPLICATIONS}

The tension pointed out by Forman is not solved by taking physical distance out of the equation. This presents a problem for those who think we can transcend conventionality by reflecting on the moral norms of our culture from the perspective of an impartial spectator. For, unless we can also somehow take psychological distance out of the equation, it is hard to see how we could resolve the tension and be both impartial and well-informed at the same time. That is not to say that such a resolution is impossible. However, as long as we have not resolved this question, appeals to a spectator who we simply stipulate as being impartial and well-informed will be of no help to us. If we cannot trust ourselves to be both impartial and well-informed, no appeal to the idea of an impartial and well-informed spectator would give us the critical distance we need on our moral culture.

Of course, for those who, like Forman, were already convinced that the impartial spectator could not help us transcend convention, this conclusion might not seem threatening. However, as noted in the introduction, the reasons to want to save the impartial spectator extend beyond this debate. Even among those who think the impartial spectator cannot critique a given conventional standard of propriety, it is commonly accepted that an impartial spectator can criticise the partial or ill-informed application of that standard to a particular situation (Fleischacker 2011, 28-29). Yet, if the above argument holds, it seems we might lose even this. Another way of putting the problem is to say that, if impartiality and understanding stand opposed even in our psychologies, then the ideal of the impartial and well-informed spectator may turn out to be out of reach because it is psychologically unrealistic.

Why, one might ask, is this a problem? After all, an ideal is something we had better not be able to achieve, if we are to have something to strive for. That might have been a fair point, if it were not for the fact that one of the supposed virtues of Smith's theory, and one of the things that makes TMS relevant today as an alternative to later theoretical developments, is precisely that the ideal of the impartial spectator is supposed to be a realistic, achievable ideal. When Smith first joins the adjective "impartial" to the noun "spectator", the spectator in question is a real person, someone like you or me (TMS, I.i.5.4, 30). When 
Smith moves on to discuss how we judge ourselves (in analogy to how we judge others), the impartial spectator comes to stand for the idea of such a person; someone we can imagine being present, whether or not she actually is. However, even in the shape of this idea-which, subsequently, becomes our ideal-the impartial and well-informed spectator retains its element of realism, remains a point of view we can in principle inhabit, if not always in practice (see for example TMS, III.3.4, 158).

This in contrast to later, more explicitly idealised conceptions of the impartial spectator, such as Roderick Firth's "ideal observer" (1952, 321). Where Smith says that an impartial spectator must be wellinformed, Firth posits that the ideal observer is both omniscient and "omnipercipient"-all-knowing and able to imaginatively visualise anything (Firth 1952, 333-335). Where Smith's impartial spectator is one who is disinterested or dispassionate in a given situation, Firth's ideal observer is "entirely lacking in particular interests" and incapable of emotions like jealousy-or even incapable of emotions altogether (Firth 1952, 335-340). In other words, the ideal observer is truly ideal. This is a reflection of the job for which Firth formed it. The ideal observer is meant to provide a theoretical grounding for the possibility of objective moral truth, without the "queer" metaphysics usually involved in realist accounts of moral objectivity (Mackie 1977, 38). The ideal observer is not an actual person, but a purely hypothetical entity (Firth 1952, 325).

Although TMS is sometimes presented as an early version of Ideal Observer Theory (for example by Rawls 1999, 161), Smith scholars tend to reject this view (see for example Broadie 2006, 184; Fleischacker 2016, 274; Frazer 2016; Haakonssen 2002, xviii; Raphael 1975, 94-96; Weinstein 2016, 353; and, more obliquely, Carrasco and Fricke 2016; Sayre-McCord 2010). The impartial spectator, these authors argue, is not some abstract philosopher's invention, some purely theoretical device around which to build a metaethics of moral truth. The impartial spectator is supposed to be a workable ideal for everyday moral judgement-indeed, if Smith is right, the impartial spectator is our ideal: the ideal we already, if tacitly, endorse and aspire to (TMS, III.3.2-3, 156157). The conclusion, though often implicit, is that this slightly nonideal realism also makes the impartial spectator better suited as an ideal for actual, everyday moral judgement compared to the unachievable ideal observer. 
Therefore, that pesky second adjective 'well-informed' throws a wrench, not into a philosopher's attempt at grounding the possibility of something like objective moral truth (as Firth attempts to do with his ideal observer), but into our actual attempts at being fair and impartial (which is what Smith takes himself to be describing). Granted, the fact that there is a tension between understanding and being impartial is less problematic than the extreme kind of idealism involved in the ideal observer. However, for the purposes of everyday moral deliberations, the two ideals may turn out to be on a par.

There are (at least) three ways to respond to this. The first is to note that psychological studies like those reviewed in this article reveal tendencies, not hard limits on what we can and cannot achieve. Hence, we may be able to control for the psychological tension between understanding and impartiality if only we try. ${ }^{17}$ This response merits closer attention than I am able to give it here, indeed it merits attention from researchers working within the framework of CLT. However, extant research on our ability to consciously control for bias in our judgements throws a relatively pessimistic light on the prospects of this first response (see for example Lilienfeld, Ammirati, and Landfield 2009). Therefore, it behoves us to consider the two other kinds of responses as well.

The second is to follow the example of Jason Kawall (2006), who, in response to Geoffrey Sayre-McCord (1994), has made a similar argument against David Hume's supposedly non-ideal "general point of view" (Kawall 2006, 370). Kawall argues, 1) that the general point of view is just as psychologically unrealistic as is the ideal observer, but 2) that it does not matter whether our moral ideals are psychologically realistic and, therefore, 3) that the ideal observer is preferable to the general point of view in virtue of its claim to all-seeing, all-knowing universality (which, among other things, would allow it to critique conventional standards of propriety). If I am right, the same argument could be made about Smith's impartial spectator. However, since adherents of non-ideal spectator theories object to 2), Kawall's alternative is unlikely to be adopted by them.

What about the third response? Well, we could revise the impartial spectator to make it even less of an ideal, or, rather, make it non-ideal in such a way that it again becomes a psychologically realistic ideal. What would it take to make the impartial spectator such an ideal? Answering

${ }^{17}$ Thanks to an anonymous reviewer for this suggestion. 
that question would take an investigation that I cannot begin, let alone finish, within the scope of this article. However, for those who find in TMS a sketch of an adequately explanatory and interestingly justificatory account of moral judgement, it is, I think, an investigation worth pursuing.

\section{CONCLUSION}

In an article on the foreign travels of German Members of Parliament, the political scientist Berit Bliesemann de Guevara recounts how one of her informants summed up the problem of proximity: "ignorance protects from granting', meaning that it is much harder to reject funding for a project once you have been on site, seen the project and met the people behind it" (Guevara 2016, 66).

The above argument amounts to the claim that this is true also for purely imaginary transpositions. Bringing the case home suffices to produce proximity bias in moral judgements. To the extent that becoming well-informed requires us to bring home to us the cases of those we judge, then the tension between understanding and impartiality defies easy resolution-even if we take physical distance out of the equation. The impartial and well-informed spectator remains an elusive ideal.

How we respond to this depends on what we want from our ideal. If we want an ideal that makes sense of how we can escape the confines of moral conventions, and, moreover, is usable for everyday moral judgements, we would do well to reconsider the contours of the impartial and well-informed spectator. How impartial? How informed? Those are questions for future research.

\section{REFERENCES}

Agerström, Jens, and Fredrik Björklund. 2009. “Temporal Distance and Moral Concerns: Future Morally Questionable Behavior is Perceived as More Wrong and Evokes Stronger Prosocial Intentions." Basic and Applied Social Psychology 31 (1): 49-59.

Agerström, Jens, and Fredrik Björklund. 2013a. "Temporal Construal and Moral Motivation." In Handbook of Moral Motivation: Theories, Models, Applications, edited by Karin Heinrichs, Fritz Oser, and Terence Lovat, 181-193. Rotterdam: Sense Publishers.

Agerström, Jens, and Fredrik Björklund. 2013b. "Why People With an Eye Toward the Future Are More Moral: The Role of Abstract Thinking." Basic and Applied Social Psychology 35 (4): 373-381. 
Batson, C. Daniel, David A. Lishner, Amy Carpenter, Luis Dulin, Sanna Harjusola-Webb, Eric L. Stocks, Shawna Gale, Omar Hassan, and Brenda Sampat. 2003. “. . . As you Would have Them Do Unto You': Does Imagining Yourself in the Other's Place Stimulate Moral Action?" Personality and Social Psychology Bulletin 29 (9): 11901201.

Broadie, Alexander. 2006. "Sympathy and the Impartial Spectator." In The Cambridge Companion to Adam Smith, edited by Knud Haakonssen, 158-188. Cambridge: Cambridge University Press.

Carrasco, María Alejandra, and Christel Fricke. 2016. "Adam Smith's Impartial Spectator." Econ Journal Watch 13 (2): 249-263.

Conway, Paul, and Johanna Peetz. 2012. "When Does Feeling Moral Actually Make You a Better Person? Conceptual Abstraction Moderates Whether Past Moral Deeds Motivate Consistency or Compensatory Behavior." Personality and Social Psychology Bulletin 38 (7): 907-919.

Coplan, Amy. 2011. "Will the Real Empathy Please Stand up? A Case for a Narrow Conceptualization." The Southern Journal of Philosophy 49 (S1): 40-65.

Cowan, Nelson. 2001. "The Magical Number 4 in Short-Term Memory: A Reconsideration of Mental Storage Capacity." Behavioral and Brain Sciences 24 (1): 87-114.

Darwall, Stephen. 1999. "Sympathetic Liberalism: Recent Work on Adam Smith." Philosophy \& Public Affairs 28 (2): 139-164.

Englich, Birte, Thomas Mussweiler, and Fritz Strack. 2005. "The Last Word in Court-A Hidden Disadvantage for the Defense." Law and Human Behavior 29 (6): 705-722.

Eyal, Tal, and Nira Liberman. 2012. "Morality and Psychological Distance: A Construal Level Theory Perspective." In The Social Psychology of Morality: Exploring the Causes of Good and Evil, edited by Mario Mikulincer, and Phillip R. Shaver, 185202. Washington, DC: American Psychological Association.

Eyal, Tal, Nira Liberman, and Yaacov Trope. 2008. "Judging Near and Distant Virtue and Vice." Journal of Experimental Social Psychology 44 (4): 1204-1209.

Eyal, Tal, Nira Liberman, and Yaacov Trope. 2014. "Thinking of Why a Transgression Occurred May Drawn Attention to Extenuating Circumstances: A Comment on Žeželj \& Jokić Replication.” Social Psychology 45 (4): 329-331.

Firth, Roderick. 1952. "Ethical Absolutism and the Ideal Observer." Philosophy and Phenomenological Research 12 (3): 317-345.

Fleischacker, Samuel. 2011. "Adam Smith and Cultural Relativism." Erasmus Journal for Philosophy and Economics 4 (2): 20-41.

Fleischacker, Samuel. 2016. "Adam Smith's Impartial Spectator: Symposium Remarks.” Econ Journal Watch 13 (2): 273-283.

Forman-Barzilai, Fonna. 2010. Adam Smith and the Circles of Sympathy: Cosmopolitanism and Moral Theory. Cambridge: Cambridge University Press.

Frazer, Michael L. 2016. "Natural and Artificial Impartiality." Econ Journal Watch 13 (2): 284-297.

Freiin von Villiez, Carola. 2011. "Adam Smith's Story of Moral Progress.” The Adam Smith Review 6: 30-45.

Fricke, Christel. 2011. "Adam Smith and 'the Most Sacred Rules of Justice'." The Adam Smith Review 6: 46-74. 
Galinsky, Adam D., Gillian Ku, and Cynthia S. Wang. 2005. "Perspective-Taking and Self-Other Overlap: Fostering Social Bonds and Facilitating Social Coordination." Group Processes \& Intergroup Relations 8 (2): 109-124.

Gilbert, Daniel T., and Timothy D. Wilson. 2007. "Prospection: Experiencing the Future." Science 317 (5843): 1351-1354.

Gino, Francesca, and Adam D. Galinsky. 2012. "Vicarious Dishonesty: When Psychological Closeness Creates Distance from One's Moral Compass." Organizational Behavior and Human Decision Processes 119 (1): 15-26.

Gong, Han, and Douglas L. Medin. 2012. "Construal Levels and Moral Judgment: Some Complications." Judgment and Decision Making 7 (5): 628-638.

Griswold, Charles L. 2010. "Smith and Rousseau in Dialogue." The Adam Smith Review 5: 59-84.

Guevara, Berit Bliesemann de. 2016. "Journeys to the Limits of First-Hand Knowledge: Politicians' On-Site Visits in Zones of Conflict and Intervention." Journal of Intervention and Statebuilding 10 (1): 56-76.

Haakonssen, Knud. 2002. "Introduction." In The Theory of Moral Sentiments, by Adam Smith, edited by Knud Haakonssen, vii-xxiv. Cambridge: Cambridge University Press.

Haidt, Jonathan. 2001. "The Emotional Dog and Its Rational Tail: A Social Intuitionist Approach to Moral Judgment." Psychological Review 108 (4): 814-834.

Haidt, Jonathan, Silvia Helena Koller, and Maria G. Dias. 1993. "Affect, Culture, and Morality, or Is It Wrong to Eat Your Dog?” Journal of Personality and Social Psychology 65 (4): 613-628.

Hepach, Robert, and Gert Westermann. 2013. "Infants' Sensitivity to the Congruence of Others' Emotions and Actions." Journal of Experimental Child Psychology 115 (1): 16-29.

Jahoda, Gustav. 2005. "Theodor Lipps and the Shift from 'Sympathy' to 'Empathy'." Journal of the History of the Behavioral Sciences 41 (2): 151-163.

Johnson, Mark. 2014 [1993]. Moral Imagination: Implications of Cognitive Science for Ethics. Chicago: University of Chicago Press. Kindle Edition.

Kawall, Jason. 2006. "On the Moral Epistemology of Ideal Observer Theories.” Ethical Theory and Moral Practice 9 (3): 359-374.

Kruger, Justin, and Matt Evans. 2004. "If You Don't Want to be Late, Enumerate: Unpacking Reduces the Planning Fallacy." Journal of Experimental Social Psychology 40 (5): 586-598.

Levine, Linda J., Heather C. Lench, and Martin A. Safer. 2009. "Functions of Remembering and Misremembering Emotion." Applied Cognitive Psychology 23 (8): 1059-1075.

Liberman, Nira, Yaacov Trope, Sean M. McCrea, and Steven J. Sherman. 2007. "The Effect of Level of Construal on the Temporal Distance of Activity Enactment." Journal of Experimental Social Psychology 43 (1): 143-149.

Lilienfeld, Scott O., Rachel Ammirati, and Kristin Landfield. 2009. "Giving Debiasing Away: Can Psychological Research on Correcting Cognitive Errors Promote Human Welfare?" Perspectives on Psychological Science 4 (4): 390-398.

Luguri, Jamie B., Jaime L. Napier, and John F. Dovidio. 2012. "Reconstruing Intolerance: Abstract Thinking Reduces Conservatives' Prejudice Against Nonnormative Groups." Psychological Science 23 (7): 756-763. 
Mackie, John L. 1977. Ethics: Inventing Right and Wrong. Harmondsworth: Penguin Books.

Maibom, Heidi L., ed. 2017. The Routledge Handbook of Philosophy of Empathy. London and New York, NY: Routledge, Taylor \& Francis Group.

Mårtensson, Erika. 2017. "Construal Level Theory and Moral Judgments: How Thinking Abstractly Modifies Morality.” Journal of European Psychology Students 8 (1): 3040.

Mesoudi, Alex, Andrew Whiten, and Robin Dunbar. 2006. "A Bias for Social Information in Human Cultural Transmission." British Journal of Psychology 97 (3): 405-423.

Messervey, Deanna L. 2008. Time and Time Again: Cultural Differences in Construal Levels. PhD Thesis, Queens University.

Meyer, Meghan L., Shelley E. Taylor, and Matthew D. Lieberman. 2015. "Social Working Memory and Its Distinctive Link to Social Cognitive Ability: An fMRI Study." Social Cognitive and Affective Neuroscience 10 (10): 1338-1347.

Nahemow, Lucille, and M. Powell Lawton. 1975. "Similarity and Propinquity in Friendship Formation." Journal of Personality and Social Psychology 32 (2): 205213.

Newcomb, Theodore M. 1956. "The Prediction of Interpersonal Attraction." The American Psychologist 11 (11): 575-586.

Nussbaum, Shiri, Nira Liberman, and Yaacov Trope. 2006. "Predicting the Near and Distant Future.” Journal of Experimental Psychology: General 135 (2): 152-161.

Pashler, Harold, Noriko Coburn, and Christine R. Harris. 2012. "Priming of Social Distance? Failure to Replicate Effects on Social and Food Judgments." PLoS ONE 7 (8): 1-6.

Raphael, David D. 1975. “The Impartial Spectator.” In Essays on Adam Smith, edited by Andrew S. Skinner, and Thomas Wilson, 83-99. Oxford: Clarendon Press.

Rawls, John. 1999. A Theory of Justice: Revised Edition. Cambridge, MA: The Belknap Press of Harvard University Press.

Sayre-McCord, Geoffrey. 1994. “On Why Hume’s 'General Point of View’ Isn't Ideal-and Shouldn't Be." Social Philosophy and Policy 11 (1): 202-228.

Sayre-McCord, Geoffrey. 2010. "Sentiments and Spectators: Adam Smith's Theory of Moral Judgment." The Adam Smith Review 5: 123-144.

Smith, Adam. 2002. The Theory of Moral Sentiments, edited by Knud. Haakonssen. Cambridge: Cambridge University Press.

Stiller, James, and Robin I. M. Dunbar. 2007. "Perspective-Taking and Memory Capacity Predict Social Network Size." Social Networks 29 (1): 93-104.

Stinson, Linda, and William Ickes. 1992. "Empathic Accuracy in the Interactions of Male Friends Versus Male Strangers." Journal of Personality and Social Psychology 62 (5): 787-797.

Strawson, Peter F. 1985. Scepticism and Naturalism: Some Varieties. London: Methuen \& Co. Ltd.

Suddendorf, Thomas, and Michael C. Corballis. 2007. "The Evolution of Foresight: What Is Mental Time Travel, and Is It Unique to Humans?" Behavioral and Brain Sciences 30 (3): 299-313.

Thorstensen, Erik. 2011. "Mennesket, Moralen og Forståelsen. Maksimen «tout comprendre, c'est tout pardonner» i Folkemordsforskningen Sett i Lys av Dens Historie." Etter Lemkin 3 (1): 8-25. 
Trope, Yaacov, and Nira Liberman. 2010. "Construal-Level Theory of Psychological Distance." Psychological Review 117 (2): 440-463.

Weinstein, Jack Russell. 2016. "My Understanding of Adam Smith's Impartial Spectator." Econ Journal Watch 13 (2): 351-358.

Williams, Lawrence E., and John A. Bargh. 2008. "Keeping One's Distance: The Influence of Spatial Distance Cues on Affect and Evaluation." Psychological Science 19 (3): 302-308.

Williams, Lawrence E., Randy Stein, and Laura Galguera. 2014. "The Distinct Affective Consequences of Psychological Distance and Construal Level." Journal of Consumer Research 40 (6): 1123-1138.

Wong, Vincent C., and Robert S. Wyer. 2016. "Mental Traveling Along Psychological Distances: The Effects of Cultural Syndromes, Perspective Flexibility, and Construal Level." Journal of Personality and Social Psychology 111 (1): 17-33.

Žeželj, Iris L., and Biljana R. Jokić. 2014. "Replication of Experiments Evaluating Impact of Psychological Distance on Moral Judgment.” Social Psychology 45 (3): 223-231.

Sveinung Sivertsen is a $\mathrm{PhD}$ candidate at the University of Bergen, Department of Philosophy. His research focuses on the moral philosophy of Adam Smith, and in particular on how modern psychological research can cast new light on old problems in Smith's sentimentalist ethics.

Contact e-mail: <sveinung.sivertsen@uib.no> 